\title{
Coincidence Detection and Stress Modulation of Spike Time-Dependent Long-Term Depression in the Hippocampus
}

\author{
Pitt Niehusmann, ${ }^{1 \star}$ Gabriel Seifert, ${ }^{1 \star}$ Kristin Clark, ${ }^{1}$ Hasan C. Atas, ${ }^{1}$ Inga Herpfer, ${ }^{1}$ Bernd Fiebich, ${ }^{1}$ \\ Josef Bischofberger, ${ }^{2,3}$ and Claus Normann ${ }^{1}$ \\ ${ }^{1}$ Department of Psychiatry and ${ }^{2}$ Institute of Physiology, University of Freiburg, D-79104 Freiburg, Germany, and ${ }^{3}$ Institute of Physiology, University of \\ Basel, CH-4056 Basel, Switzerland
}

\begin{abstract}
Associative long-term depression (LTD) in the hippocampus is a form of spike time-dependent synaptic plasticity that is induced by the asynchronous pairing of postsynaptic action potentials and EPSPs. Although metabotropic glutamate receptors (mGluRs) and postsynaptic $\mathrm{Ca}^{2+}$ signaling have been suggested to mediate associative LTD, mechanisms are unclear further downstream. Here we show that either mGluR1 or mGluR5 activation is necessary for LTD induction, which is therefore mediated by group I mGluRs. Inhibition of postsynaptic phospholipase C, inositol-1,4,5-trisphosphate, and PKC prevents associative LTD. Activation of PKC by a phorbol ester causes a presynaptic potentiation of synaptic responses and facilitates LTD induction by a postsynaptic mechanism. Lithium, an inhibitor of the PKC pathway, inhibits LTD and the presynaptic and postsynaptic effects of the phorbol ester. Furthermore, LTD is sensitive to the postsynaptic application of synthetic peptides that inhibit the interaction of AMPA receptors with PDZ domains, suggesting an involvement of protein interacting with C-kinase 1 (PICK1)-mediated receptor endocytosis. Finally, enhanced PKC phosphorylation, induced by behavioral stress, is associated with enhanced LTD. Both increased PKC phosphorylation and stress-induced LTD facilitation can be reversed by lithium, indicating that this clinically used mood stabilizer may act on synaptic depression via PKC modulation. These data suggest that PKC mediates the expression of associative LTD via the PICK1-dependent internalization of AMPA receptors. Moreover, modulation of the PKC activity adjusts the set point for LTD induction in a behavior-dependent manner.
\end{abstract}

\section{Introduction}

Spike time-dependent plasticity (STDP) depends on temporal association between presynaptic and postsynaptic activity. The order of presynaptic and postsynaptic spiking determines the sign of long-term modification of a variety of glutamatergic synapses in the brain (Dan and Poo, 2006). Within a time window of several tens of milliseconds, multiple repetitions of a sequence in which an EPSP induced by presynaptic stimulation precedes a postsynaptic action potential $(\mathrm{EPSP} \rightarrow \mathrm{AP})$ will cause long-term potentiation (LTP), whereas an $\mathrm{AP} \rightarrow$ EPSP sequence will result in long-term depression (LTD).

In a simplistic model, two basic signals are required for the induction of STDP: the presynaptic release of glutamate and the backpropagating postsynaptic action potential. Which cellular structures detect the temporal sequence of these signals and translate this information into a potentiation $(\mathrm{EPSP} \rightarrow \mathrm{AP})$ or depression ( $\mathrm{AP} \rightarrow \mathrm{EPSP}$ ) of synaptic strength? The first candidate is the postsynaptic NMDA receptor. NMDA receptors are largely blocked by $\mathrm{Mg}^{2+}$ at resting membrane potentials. This block can

Received Dec. 28, 2009; accepted March 10, 2010.

This work was supported by grants from the Deutsche Forschungsgemeinschaft to C.N. (No 370/3) and J.B. (Bi $642 / 2$ and SFB 780). We thank Sarah Greiner for performing the Western blots.

*P.N. and G.S. contributed equally to this work.

Correspondence should be addressed to Claus Normann, Department of Psychiatry, University of Freiburg,

Hauptstrasse 5, D-79104 Freiburg, Germany. E-mail: claus.normann@uniklinik-freiburg.de.

P. Niehusmann's present address: Department of Neuropathology, University of Bonn, Germany.

D0I:10.1523/JNEUROSCI.6411-09.2010

Copyright $\odot 2010$ the authors $\quad 0270-6474 / 10 / 306225-11 \$ 15.00 / 0$ be relieved by action potential-induced depolarization so that binding of glutamate can cause influx of $\mathrm{Ca}^{2+}$ into the postsynaptic neuron; this is usually regarded as the initial step in synaptic plasticity. A standard model of long-term plasticity postulates that different cascades of signaling events are triggered by highand low-level postsynaptic $\mathrm{Ca}^{2+}$ elevation; moderate levels of $\mathrm{Ca}^{2+}$ above the baseline induce LTD, whereas higher levels result in LTP (Lisman, 1989). Although this model might be valid for some forms of frequency-dependent homosynaptic plasticity, it is questionable whether it could account for the more complex rules of STDP, specifically the sequence-specific induction of LTD and LTP by repeated AP $\rightarrow$ EPSP and EPSP $\rightarrow$ AP sequences, respectively.

In a previous series of experiments (Normann et al., 2000), we have shown that the induction of associative LTD by an asynchronous pairing protocol could be blocked by the metabotropic glutamate receptor (mGluR)-antagonist MCPG [( $S)$ - $\alpha$-methyl4-carboxyphenyl-glycine] and the $\mathrm{N}$-type $\mathrm{Ca}^{2+}$ channel antagonist $\omega$-conotoxin GVIa, but not by the NMDA receptor antagonist D-AP5 (D (-)-2-amino-5-phosphopentanoic acid). Similar results were reported for mGluR-dependent LTD induced by either low-frequency stimulation or application of mGluR agonists (Bolshakov and Siegelbaum, 1994; Oliet et al., 1997; Huber et al., 2000).

To account for non-NMDA-dependent forms of LTD, Karamarkar and Buonomano (2002) have proposed a second coincidence detector. Notably, the PKC-pathway fulfills the requirements of a system that is capable of processing presynaptic and 
postsynaptic information in the absence of NMDA receptor activation. To modify synaptic transmission, the PKC-pathway undergoes the following steps: (1) it is activated downstream of metabotropic glutamate receptors, (2) it is regulated by postsynaptic calcium, and (3) interacts with AMPA receptor trafficking. Here, we examine the role of the PKC pathway in associative long-term synaptic depression and provide evidence for a new coincidence detector in STDP.

\section{Materials and Methods}

Animals and slice preparation. Juvenile Wistar rats (postnatal day 14-21) were used for experiments. The animals were killed by decapitation, in accordance with national and institutional guidelines. Transverse slices were cut from the hippocampal region $(300 \mu \mathrm{m})$ with a vibratome (DTK-1000, Dosaka). The slices were incubated at $35^{\circ} \mathrm{C}$ for $20 \mathrm{~min}$ and then stored at room temperature. For dissection, slicing, and storage, a physiological saline solution was used containing the following (in $\mathrm{mM}$ ): $125 \mathrm{NaCl}$, 25 glucose, $25 \mathrm{NaHCO}_{3}, 1.25 \mathrm{NaH}_{2} \mathrm{PO}_{4}, 2.5 \mathrm{KCl}, 2 \mathrm{CaCl}_{2}$, and $1 \mathrm{MgCl}_{2}$ (equilibrated with $95 \% \mathrm{O}_{2} / 5 \% \mathrm{CO}_{2}$ ).

Electrophysiology. After transfer to the recording chamber, the slices were superfused at a flow rate of $5-10 \mathrm{ml} / \mathrm{min}$ (chamber volume, $1.5-2$ $\mathrm{ml}$ ) with saline solution containing $20 \mu \mathrm{M}$ picrotoxin to isolate excitatory neurotransmission. Pyramidal neurons in the CA1 region of the hippocampus were identified visually and by their characteristic firing frequency adaptation in response to long depolarizing current pulses. Infrared differential contrast video microscopy was used (Axioskop 2 FS plus, Zeiss; IMAGO-VGA, Till Photonics). Patch pipettes were pulled from borosilicate glass tubing (outer diameter, $2.0 \mathrm{~mm}$; wall thickness, $0.5 \mathrm{~mm}$; open patch pipette resistance, 3-5 M $\Omega$; Hilgenberg). Patch pipettes were filled with a filtered solution containing the following (in $\mathrm{mm}$ ): $135-145 \mathrm{~K}$-gluconate, $20 \mathrm{KCl}, 2 \mathrm{MgCl}_{2}, 2-4$ sodium adenosine triphosphate, 0.3 sodium guanosine $5^{\prime}$-triphosphate, 10 HEPES, and 0.1 EGTA (for LTP measurements) or 0.5 EGTA (for LTD and EPSP measurements), equilibrated with $\mathrm{KOH}$ to $\mathrm{pH}$ 7.3. The interval between braking into the whole-cell mode and the onset of the induction protocol was standardized to $\sim 15 \mathrm{~min}$. All patch-clamp recordings were made with an EPC-9 amplifier (HEKA). Signals were filtered at 5 and $10 \mathrm{kHz}$ and stored online. For data acquisition and analysis, Pulse and PulseFit (HEKA), Igor Pro (Wavemetrics), and Mini Analysis software (Synaptosoft) were used.

The resting membrane potentials of most neurons were between -72 and $-68 \mathrm{mV}$ and the holding potential was $-70 \mathrm{mV}$. Input and series resistances were continuously monitored over the course of the experiments by applying a $500 \mathrm{~ms}$ current pulse (that led to a hyperpolarization by $\sim 5 \mathrm{mV}$ ) after every 10th EPSP. The series resistance values of all experiments were between 10 and $37 \mathrm{M} \Omega$. Experiments were discarded if the series resistance changed by $>30 \%$ over the course of the experiment, if the difference in the membrane potential between the start and the termination of the experiment exceeded $5 \mathrm{mV}$, or if the cells showed evidence of ictal discharge. Experiments examining modulation of synaptic plasticity were interleaved with control experiments, which were merged in Figures $1 C$ and $2 \mathrm{C}$. All experiments were performed at $32^{\circ} \mathrm{C}$.

Presynaptic Schaffer collateral fibers were stimulated with a stimulus isolator (Stimulator 2100, A-M Systems). A pipette with a resistance of 1-3 $\mathrm{M} \Omega$, filled with HEPES-buffered $\mathrm{NaCl}$ solution, was placed in the stratum radiatum of the CA1 region, $20-50 \mu \mathrm{M}$ away from the pyramidal cell layer. To perform orthodromic stimulation, $200 \mu$ s voltage pulses of $10-100 \mathrm{~V}$ (mostly $\sim 30 \mathrm{~V}$ ) were delivered at a frequency of $0.1 \mathrm{~Hz}$. The stimulation intensity was set to evoke an initial subthreshold EPSP amplitude of 3-6 $\mathrm{mV}$. Induction protocols and wash-in of substances were started after a stable EPSP baseline had been recorded for $10 \mathrm{~min}$.

Western blot. Animals were killed by decapitation and both hippocampi were dissected. Brain tissues were subjected to $1.3 \times$ SDScontaining sample buffer containing $100 \mu \mathrm{M}$ orthovanadate. Tissues were homogenized by 20 -fold sonication and centrifuged at $1400 \times \mathrm{g}$. Protein contents were measured using the bicinchoninic acid method (BCA protein determination kit from Pierce). Samples were boiled after the addition of bromophenol blue and dithiothreitol (final concentra- tion $10 \mathrm{~mm}$ ) before electrophoresis. For Western blotting, $80 \mu \mathrm{g}$ of protein from each sample was subjected to SDS-PAGE on a 7.5\% gel under reducing conditions. Proteins were transferred onto a polyvinylidene fluoride membrane (Millipore) by semidry blotting. The membrane was blocked overnight at $4^{\circ} \mathrm{C}$ using Rotiblock (Roth) before being incubated with the primary antibody. To detect phosphorylated PKC $\alpha$, the membrane was incubated for $2 \mathrm{~h}$ with anti-phospho PKC $\alpha / \beta$ II (No. 9375, 1:2000, New England Biolabs) diluted in Tris-buffered saline containing $0.1 \%$ Tween 20 (Merck) and 2\% bovine serum albumin (Sigma). After washing (three times for 15 min each in saline containing $0.1 \%$ Tween 20 ), proteins were detected with peroxide-coupled donkey anti-rabbit IgG (1:10,000, GE Healthcare) using chemiluminescence reagents (GE Healthcare). Rabbit anti actin (1:5000, Sigma-Aldrich) was used to determine equal loading and for quantification of the Western signals. Western blot films were scanned densitometrically using ScanPack 2.0 Software from Biometra.

Data analysis and statistics. All values are given as mean \pm SEM; error bars in the figures also represent SEM. Averaged EPSP amplitudes in amplitude-time plots represent means from four to seven consecutive EPSPs. To calculate the mean EPSP amplitude for quantification of synaptic plasticity or the effect of wash-in of substances, the maximal amplitude of the last 60 EPSPs immediately before the start of the induction protocol or the wash-in and 20-30 min after termination of the intervention were averaged. The significance of EPSP amplitude or slope changes after induction or wash-in was assessed by a Wilcoxon signed rank test. Initial EPSP slopes were estimated by analyzing the EPSP rise from $20 \%$ to $40 \%$ of its maximal amplitude (where the increase of the EPSP was approximately linear). For the analysis of the coefficient of variation $(\mathrm{CV})(\mathrm{SD} / \mathrm{mean})$, the inverse square of the $\mathrm{CV}$ of the first 30 EPSP slopes after the induction protocol was divided by the inverse square of the CV of the last 30 EPSP slopes before the onset of the induction protocol and plotted against the normalized slope of the EPSPs. Differences between separate series were analyzed by a MannWhitney test at a significance level of 0.05. GraphPad Prism software was used to average and plot EPSP amplitudes and for statistical analyses.

Stress protocol. For the stress experiments, rats were immobilized in a Plexiglas tube (Harvard Apparatus) for $30 \mathrm{~min}$. Electrical shocks were applied with two ECG electrodes to the tail of the animals using a stimulator $(0.3 \mathrm{~mA}$ direct current for $1 \mathrm{~s})$. Immediately after the end of the stress protocols, the animals were killed and brain slices were prepared. These experiments were reviewed and approved by the local animal welfare committee.

Chemicals. All chemicals were obtained from Sigma-Aldrich or Tocris Bioscience. Agonists and antagonists were applied by bath perfusion with the exception of $\mathrm{U} 73122$, heparin (heparin sodium from porcine intestinal mucosa), $\mathrm{PKC}_{19-36}$, SB415286, and VDM-11, which were added to the intracellular solution in the recording electrode and injected into the postsynaptic cell. PDZ-interacting peptides were custom synthesized by Primm and their sequences were verified by high-pressure liquid chromatography and mass spectroscopy (pep2-EVKI: ${ }^{873}{ }^{7}$ NVYGIEEVKI ${ }^{883}$, pep2-SVKI: ${ }^{873}$ YNVYGIESVKI $^{883}$, pep2-SVKE: ${ }^{873}$ YNVYGIESVKE $^{883}$; single letter amino acid code, peptide sequence indicated as $\mathrm{NH}_{2}$ $\mathrm{COOH}$ ). Pep2-SVKI is the sequence of the last 11 amino acids of wildtype GluR2. For peptide experiments, peptides were dissolved in the intracellular solution at a concentration of $100 \mu \mathrm{M}$. These solutions also contained the protease inhibitors bestatin, leupeptin, and pepstatin A at concentrations of $100 \mu \mathrm{M}$ each.

\section{Results}

\section{Associative LTD depends on the phospholipase C-PKC pathway}

We induced associative long-term depression in hippocampal slices by asynchronous pairing of an EPSP with a postsynaptic action potential. An action potential was elicited in the postsynaptic cell and followed 20-30 ms after its onset by an EPSP (Fig. $1 A$ ). This pairing was repeated 360 times at a frequency of $1 \mathrm{~Hz}$. After asynchronous pairing, EPSP amplitudes were significantly reduced to $62.7 \pm 4.1 \%$ of baseline $(n=21, p<0.001)$ (Fig. 
A
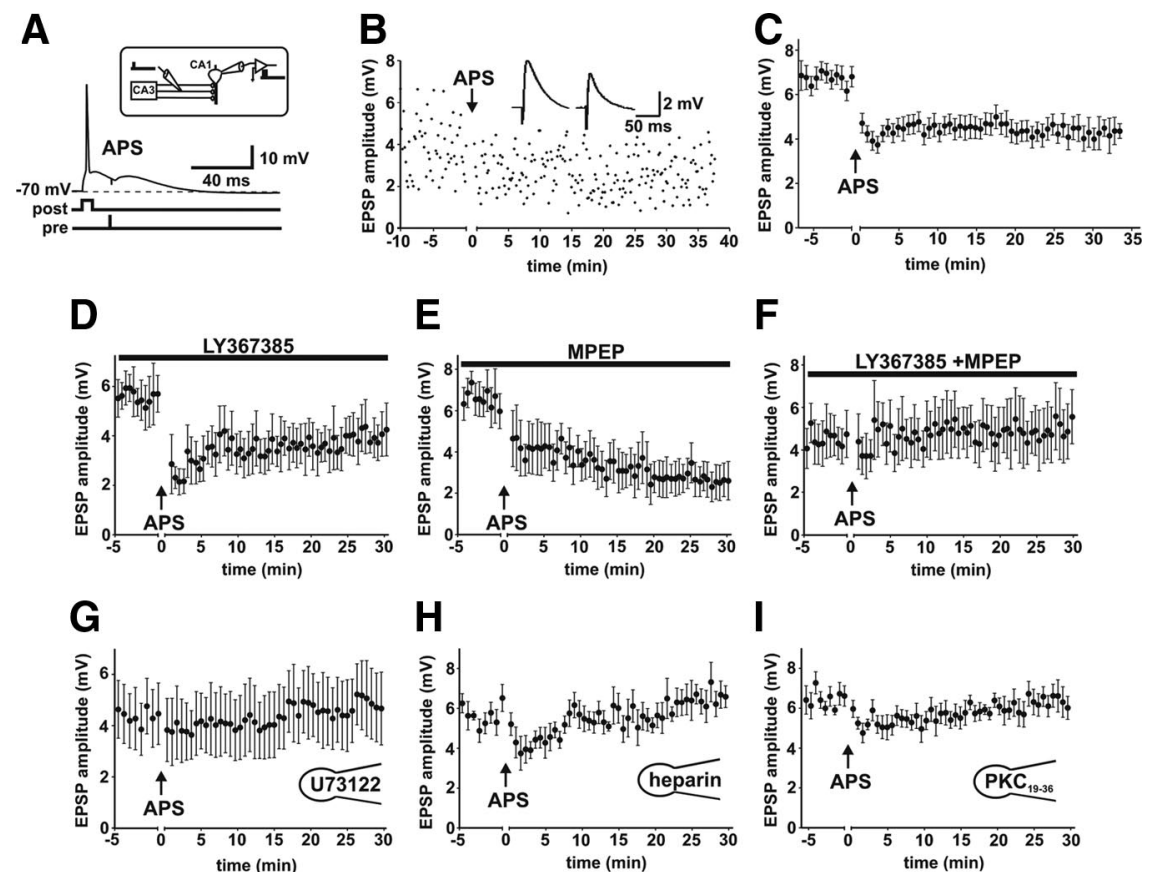

$\mathbf{F}$
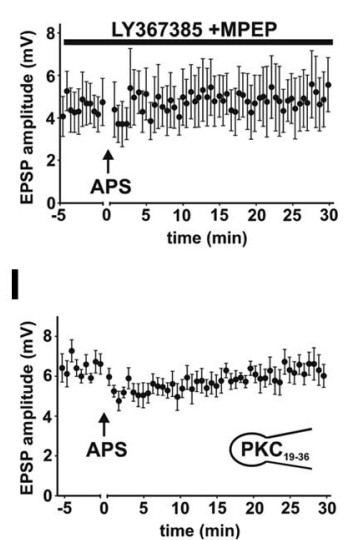

Figure 1. Associative LTD depends on the PLC/PKC pathway. A, Associative LTD was induced by asynchronous pairing of presynaptic and postsynaptic activity. An action potential was induced by current injection into the postsynaptic neuron and followed 20 ms later by an EPSP induced by Schaffer collateral stimulation. This asynchronous pairing stimulation (APS) pattern was repeated 360 times at a frequency of $1 \mathrm{~Hz}$. This induction paradigm resulted in a sustained reduction in peak EPSP amplitudes. $B$, Sample recording. Amplitude-time plot of maximal EPSP amplitudes; EPSP sample traces before and after LTD induction. C, Averaged amplitude-time plot from 21 individual experiments with asynchronous pairing stimulation resulting in an LTD of $62.7 \pm 4.1 \%$ of baseline EPSP amplitude. Subtype specificity of group I mGluR activation. D, E, The mGluR1 antagonist LY367385 $(\boldsymbol{D})$ and the $\mathrm{MGluR5}$ antagonist MPEP $(\boldsymbol{E})$ had no effect on associative LTD. $\boldsymbol{F}$, When both substances together were applied with the bath solution, LTD induction was completely prevented. Inhibition of different limbs of the PLC/PKC pathway resulted in a complete block of LTD. G, PLC was inhibited by addition of the specific PLC antagonist U73122 into the recording electrode. $\boldsymbol{H}$, Heparin (4 $\mathrm{mg} / \mathrm{ml}$ ) inhibits the release of $\mathrm{Ca}^{2+}$ ions from intracellular stores. Injection of this substance into the postsynaptic neuron prevented LTD. I, PKC ${ }_{19-36}$ specifically inhibited PKC activity and again blocked LTD induction.

$1 B, C)$. Additionally, we analyzed the initial EPSP slopes, which are less likely to be contaminated by polysynaptic signals or regenerative currents in postsynaptic neurons, and found results that are comparable to the analysis of the maximal EPSP amplitudes (decrease of the slope after LTD induction to $65.4 \pm 9.5 \%$ of its average baseline value, $n=21, p<0.005$; normalized slope decrease vs normalized EPSP amplitude decrease, $p>0.5$ ) (supplemental Fig. $1 A$, available at www.jneurosci.org as supplemental material).

In previous work, this spike time-dependent form of LTD was shown to be dependent on the activation of mGluRs and voltage-activated calcium channels, but not on NMDA receptors. Associative LTD was blocked by the group I mGluRspecific antagonist MCPG (Normann et al., 2000). Group I mGluRs comprise mGluR1 and mGluR5, both of which are thought to couple through Gq-type G-proteins (Valenti et al., 2002). It is unknown which group I mGluR subtype mediates associative LTD in the hippocampus. We therefore applied subtype-specific mGluR-antagonists during LTD induction. (+)-2-methyl-4-carboxyphenylglycine (LY367385) is highly selective for mGluR1 over mGluR5. When $100 \mu \mathrm{M}$ LY367385 was present in the bath solution, the associative pairing stimulation induced a synaptic depression to $68.8 \pm 3.8 \%$ of baseline, which was not significantly different from the amount of LTD in control solution ( $n=6, p<0.05$ vs baseline, $p>0.05$ vs control LTD) (Fig. 1D). 2-methyl-6-(phenylethynyl)-pyridine (MPEP) is a selective, noncompetitive mGluR5-antagonist. MPEP $(10 \mu \mathrm{M})$ had no effect on LTD induction (41.7 \pm $12.1 \%$ of baseline EPSP amplitude, $n=6$, $p<0.05$ vs baseline; $p>0.05$ vs control LTD) (Fig. 1E). However, when LY367385 and MPEP were applied simultaneously, LTD was completely inhibited (106.6 \pm $27.9 \%$ of baseline, $n=6, p>0.5 ; p<0.05$ vs control LTD) (Fig. $1 F$ ). This suggests that activation of either receptor is sufficient for the mGluR activation necessary for LTD induction.

Activation of mGluR1 and mGluR5 are positively coupled to phospholipase C (PLC), whose activation results in the hydrolysis of membrane-bound phosphoinositide to generate inositol-1,4,5trisphosphate $\left(\mathrm{IP}_{3}\right)$ and diacylglycerol (DAG). Further downstream, DAG activates PKC. We first tested whether activation of phospholipase $\mathrm{C}$ and the downstream pathway are necessary for LTD induction. The pyramidal neurons were dialyzed via the patch pipette with the selective PLC inhibitor U-73122 $(20 \mu \mathrm{M})$, which completely prevented the induction of LTD (106.9 \pm $29.3 \%$ of baseline EPSP amplitude, $n=5$, $p>0.5$ ) (Fig. 1G).

Heparin is an antagonist of $\mathrm{IP}_{3}$ receptors and blocks $\mathrm{Ca}^{2+}$ release from intracellular stores. Heparin $(4 \mathrm{mg} / \mathrm{ml})$ was applied by intracellular injection into the CA1 neuron via the recording electrode. Under these conditions, the associative induction protocol resulted in a shortterm depression $(75.8 \pm 6.2 \%$ of the baseline amplitude $2 \mathrm{~min}$ after the end of the induction protocol, $n=6, p<0.05)$. LTD maintenance was blocked (116.4 $\pm 9.8 \%$ of baseline amplitude, $n=6, p>0.1)$ (Fig. $1 H$ ).

The peptide $\mathrm{PKC}_{19-36}$ is a fragment of the inhibitory regulatory domain of protein kinase C (Arg-Phe-Ala-Arg-Lys-GlyAla-Leu-Arg-Gln-Lys-Asn-Val-His-Glu-Val-Lys-Asn), and is therefore a potent and specific inhibitor of PKC activity (House and Kemp, 1987). Oliet and coworkers (1997) found that NMDA-dependent forms of LTD could not be blocked by $\mathrm{PKC}_{19-36}$, whereas mGluR-dependent, nonassociative forms of hippocampal LTD induced by sustained low-frequency stimulation of the Schaffer collaterals were shown to depend on PKC activation. $\mathrm{PKC}_{19-36}(10 \mu \mathrm{M})$ was applied by postsynaptic intracellular injection. This resulted in a failure of the induction protocol to elicit LTD $(98.0 \pm 6.7 \%$ of baseline amplitude, $n=7, p>0.5$ ) (Fig. 1 I). Additionally, the EPSP slopes $20-30 \mathrm{~min}$ after LTD induction were not significantly different from baseline values (104.2 $\pm 6.4 \%$ of baseline slopes, $n=7, p>0.5)$ (supplemental Fig. $1 B$, available at www.jneurosci.org as supplemental material). These findings suggest that activation of PLC, $\mathrm{IP}_{3}$-mediated $\mathrm{Ca}^{2+}$ release, and PKC activation are necessary for the induction of stable mGluR-dependent LTD.

\section{Associative LTP is independent from postsynaptic PKC activation}

To test whether the activation of PKC is necessary for spike timedependent plasticity in general or is specific for LTD, we exam- 
ined an associative form of LTP that was induced by theta-burst stimulation using a total of 125 EPSP/AP pairings. Five EPSPs were paired with five postsynaptic action potentials at a frequency of $100 \mathrm{~Hz}$ (delay between onset of the EPSP and AP onset, $5 \mathrm{~ms}$ ). Five of these pairing sequences were repeated at $5 \mathrm{~Hz}$, and five of the resulting theta-burst blocks (one of which is depicted in Fig. 2A) were repeated at a frequency of $0.1 \mathrm{~Hz}$ (Schmidt-Hieber et al., 2004; Holderbach et al., 2007). This protocol caused a stable potentiation of the EPSP amplitude to $233.6 \pm 20.5 \%$ of the baseline $(n=12, p<0.01)$ (Fig. $2 B, C)$. Theta-burst stimulation depends on NMDA receptor, but not on mGluR, activation (Selig et al., 1995). Intracellular application of $\mathrm{PKC}_{19-36}$ had no effect on the magnitude of LTP induced by theta-burst stimulation $(202.1 \pm$ $22.14 \%, n=7, p<0.01$ vs baseline, $p>0.5$ vs control) (Fig. $2 D$ ). This is in contrast to other findings in the hippocampus in which LTP was mainly induced by tetanic highfrequency stimulation (Wang and Feng, 1992). However, using highly specific PKC inhibitors, Bortolotto and Collingridge could not confirm a role for PKC in LTP (Bortolotto and Collingridge, 2000); this is consistent with the notion that $\mathrm{PKC}$ might preferentially be involved in mGluR-dependent synaptic plasticity, i.e., associative LTD.

\section{Lithium inhibits LTD}

Lithium was found to inhibit the activity of $\mathrm{PKC} \alpha$, both in vitro and in vivo (Manji et al., 1993; Bitran et al., 1995). This effect might be due to the modulation of molecules upstream of the PKC signaling cascade, e.g., the reduction of $\mathrm{Ca}^{2+}$ release from intracellular stores by inhibition of inositol-1phosphatase (Manji et al., 1996). Alternatively, lithium might directly inhibit PKC activation. Lithium has been shown to inhibit the translocation of PKC from the cytosol of the neuron to its membrane; this occurs both acutely and after chronic application (Wang et al., 2001).

We tested the modulation of basic membrane properties, synaptic transmission, and synaptic plasticity by lithium. Lithium carbonate (2 mM) was acutely applied via bath perfusion to hippocampal brain slices. In whole-cell current-clamp recordings, lithium did not change the membrane potential or the input resistance of CA1 pyramidal cells. Neither the amplitude nor the half-width of single APs induced by brief current injection were altered (mean AP amplitude in control, $119.7 \pm 2.7 \mathrm{mV}$ vs $118.5 \pm 4.1 \mathrm{mV}$ in lithium, $n=9, p>0.5$; half-width, $2.3 \pm 0.1$ $\mathrm{ms}$ in control vs $2.1 \pm 0.2 \mathrm{~ms}$ in lithium, $n=9, p>0.1$ ) (data not shown). EPSPs were evoked by extracellular stimulation of the Schaffer collateral pathways. Lithium did not change the amplitude or the kinetics of baseline synaptic transmission when applied for $30 \mathrm{~min}$ (amplitude, $5.0 \pm 0.5 \mathrm{mV}$ in control vs $5.1 \pm 0.8$ $\mathrm{mV}$ with lithium, $n=9, p>0.5$; decay time constant, $23.96 \pm$ $3.03 \mathrm{~ms}$ in control vs $24.02 \pm 3.5 \mathrm{~ms}$ with lithium, $n=9, p>0.5$ ). Although it is possible that a different result may be obtained with higher concentrations of lithium (Higashitani et al., 1990), these data indicate that lithium does not modulate ion channels, action potential properties, or glutamate release under our conditions.
To test the effect of lithium on synaptic plasticity, LTD was again induced by asynchronous pairing stimulation. Lithium dose-dependently inhibited LTD induction ( $1 \mathrm{~mm}$ : $76.7 \pm 10.8 \%$ of baseline amplitude, $n=8, p<0.05$ vs baseline, $p<0.05$ vs control LTD; 2 mM: $91.9 \pm 7.6 \%$ of baseline amplitude, $n=7$, $p>0.5$ vs baseline, $p<0.01$ vs LTD in control solution) (Fig. $3 A$ ). Again, the analysis of the initial EPSP slopes did not differ from the time course of the maximal EPSP amplitudes (105.9 $\pm 18.0 \%$ of baseline slopes, $n=7, p>0.5$ ) (supplemental Fig. $1 C$, available at www.jneurosci.org as supplemental material). Next, LTP was induced by theta-burst stimulation. Bath application of lithium $(2 \mathrm{~mm})$ resulted in a small and nonsignificant decrease of the resulting LTP $(208.6 \pm 20.4 \%$ of baseline amplitude, $n=16$; $p<$ 0.01 vs baseline EPSP amplitude, $p>0.1$ vs LTP in control solution) (Fig. 3B). These findings suggest that, similar to the specific inhibitor $\mathrm{PKC}_{19-36}$, the acute application of lithium inhibited LTD via reduction of PKC activity. Again, LTP was not significantly affected.

Beneath its effect on PKC activation, lithium inhibits the glycogen synthase kinase-3 (GSK-3) (Klein and Melton, 1996). GSK-3 is a constitutively active serine kinase that is involved in a large number of signal transduction cascades and, more specifically, in the regulation of long-term synaptic plasticity (Peineau et al., 2008). Overexpression of GSK-3 inhibited LTP (Hernández et al., 2002), whereas LTP by itself inhibited GSK-3 and, consecutively, NMDA-dependent LTD (Hooper et al., 2007; Peineau et al., 2007). The role of GSK-3 in mGluR-dependent LTD has not yet been examined. We applied the specific GSK-3 antagonist SB415286 $(10 \mu \mathrm{M})$ intracellularly via the patch pipette. Under these conditions, there was still a significant LTD that was reduced compared with the amount of synaptic depression in control solution; however, this difference was not significant (74.9 \pm $23.9 \%$ of baseline EPSP amplitude, $n=6, p<0.05$; $p>0.05$ vs control LTD) (Fig. 3C). 

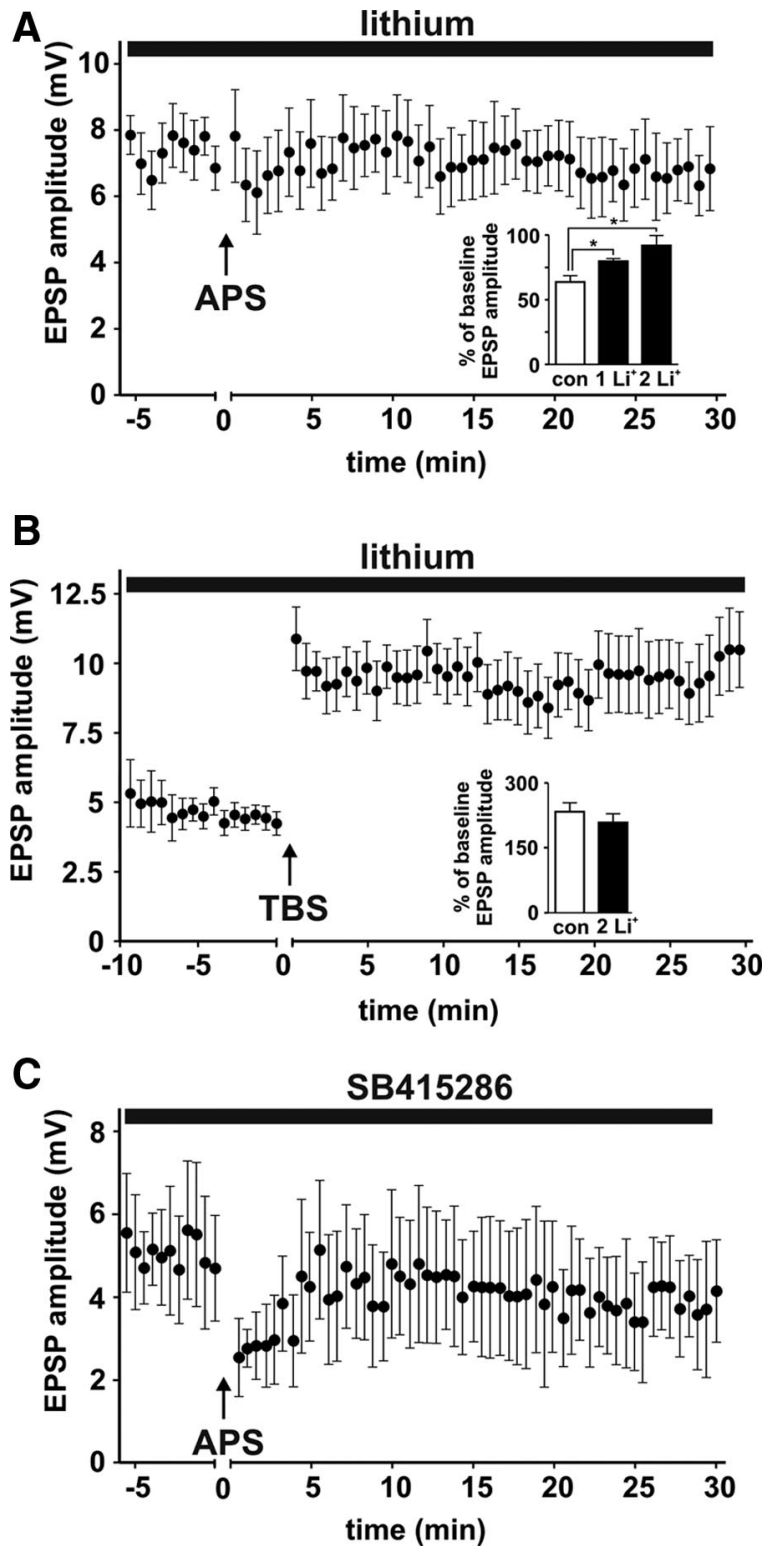

Figure 3. Lithium inhibits LTD. In this set of experiments, we used lithium as an additional pharmacological tool to inhibit PKC activity. $\boldsymbol{A}$, In the presence of lithium, asynchronous pairing stimulation (APS) failed to elicit LTD. Both 1 and $2 \mathrm{~mm}$ lithium significantly reduced the amount of LTD. B, Lithium (Li; 2 mm) had no significant effect on the magnitude of LTP evoked by theta-burst stimulation. C, The GSK-3 inhibitor SB415286 (10 $\mu \mathrm{M})$ was applied by intracellular dialysis. The induction protocol still resulted in a significantly reduced LTD.

Presynaptic and postsynaptic effects of PKC activation by a phorbol ester

So far we have shown that pharmacological reduction of PKC activity inhibits LTD. We next tested whether the converse was true: whether upregulation of PKC activity would facilitate LTD. Phorbol esters are functional analogues of DAG and activate PKC. At different synapses, bath application of phorbol esters has caused a synaptic potentiation by a mechanism that is thought to be presynaptic (Hori et al., 1999). Additionally, at the Schaffer collateral/CA1 synapse, the transient application of phorbol esters has been shown to prime LTD (Stanton, 1995).

We first assessed the presynaptic activity of the phorbol ester phorbol-12,13-dibutyrate (PDBu). Wash-in of PDBu (5 $\mu \mathrm{M})$ resulted in a massive increase in the EPSP amplitude (742.8 \pm $187.7 \%$ of baseline amplitude, $n=4, p<0.01$ ) (Fig. $4 A$ ).
Postsynaptically injected $\mathrm{PKC}_{19-36}$ did not significantly inhibit this increase, which further supports a presynaptic mechanism of action $(640.3 \pm 170.8 \%$ of baseline amplitude, $n=4, p<0.05$ vs baseline; $p>0.5$ vs PDBu wash-in) (Fig. $4 B$ ). Bath application of the selective membrane-permeable PKC antagonist Gö 6983 (10 $\mu \mathrm{M})$ had no effect on the baseline EPSP amplitude $(-1.4 \pm$ $11.7 \%, n=8, p>0.5$ ) (data not shown) but significantly reduced the potentiation of EPSP amplitudes after wash-in of PDBu (361.2 $\pm 43.6 \%$ of baseline amplitude, $n=8, p<0.01$ vs baseline, $p<0.01$ vs PDBu wash-in) (Fig. $4 B$ ). However, the increase in synaptic transmission after PDBu was not completely blocked by Gö 6983.

When PDBu was applied in the presence of lithium, the $\mathrm{PDBu}$-induced presynaptic potentiation of synaptic responses was attenuated to approximately the same amount as by the PKC antagonist Gö 6983 (263.2 $\pm 55.7 \%$ of baseline amplitude, $n=4$, $p<0.05$ vs baseline; $p<0.05$ vs PDBu wash-in) (Fig. $4 C$ ). Lithium has previously been shown to inhibit increases in neurotransmitter release upon activation of PKC by a phorbol ester. This effect of lithium has been attributed to the prevention of PKC translocation to the membrane (Wang and Friedman, 1989). Together, these findings support a partial role for PKC in the presynaptic effects of phorbol esters. Although a large body of literature has attributed the presynaptic effects of phorbol esters to activation of $\mathrm{PKC}$, a recent study postulated a role for munc13 (Rhee et al., 2002) and suggested that it is potentially responsible for the proportion of phorbol ester-induced potentiation that is not blocked by the PKC antagonist. This is consistent with recent findings that described an interdependence of PKC- and munc13-dependent pathways in presynaptic plasticity (Wierda et al., 2007).

A second, presumably postsynaptic effect of $\mathrm{PDBu}$ was an increase in the magnitude of LTD. For these experiments, the slices were preincubated with PDBu for at least $30 \mathrm{~min}$ before the whole-cell configuration was established. This allowed the recording of a stable EPSP baseline. A substantially lower stimulation intensity was needed to obtain an EPSP amplitude in the same range as those evoked in control experiments. Under these conditions, the induction protocol caused a depression of the EPSP amplitude to $35.8 \pm 7.2 \%$ of baseline, which was significantly larger than the magnitude of LTD in control solution $(n=$ $6, p<0.01$ vs baseline; $p<0.01$ vs control LTD) (Fig. $4 D$ ). Intracellular postsynaptic application of $\mathrm{PKC}_{19-36}$ completely blocked the PDBu-upregulated LTD $(99.5 \pm 4.6 \%$ of baseline amplitude, $n=7, p>0.5$ ) (Fig. $4 E$ ); this suggested a postsynaptic locus of action. Both the increased amount of LTD after PKC activation by a phorbol ester and its inhibition by a specific PKC inhibitor supports a permissive role of PKC in LTD (Stanton, 1995). Lithium again mimicked the effects of the PKC antagonist $\mathrm{PKC}_{19-36}$ and inhibited the PDBu-upregulated LTD (102.7 \pm $6.8 \%$ of baseline amplitude, $n=8, p>0.5$ ) (Fig. $4 F$ ). This suggested that lithium antagonizes $\mathrm{PKC}$ activation at both the presynaptic and postsynaptic sites.

\section{Role of PDZ proteins in the LTD mechanism}

Our results so far demonstrate that LTD is dependent on PKC and that pharmacological activation of PKC facilitates LTD. How does PKC exert its effects on LTD?

Near the resting membrane potentials, EPSPs are generated largely by currents conducted via AMPA-type glutamate receptors. AMPA receptors are highly mobile molecules that cycle rapidly into and out of the membrane of the postsynaptic density, and the dynamic regulation of AMPA receptor trafficking is 
thought to underlie many forms of synaptic plasticity (Bredt and Nicoll, 2003). AMPA receptors are heteromeric complexes of up to four combined subunits, GluR1-R4, with GluR1 and GluR2 predominantly expressed in CA1 pyramidal cells. The last four amino acids of the C-terminal region of GluR2 (SVKI) form a PDZ binding motif that is also called group II PDZ ligand. To date, three PDZ domain-containing proteins that interact with this PDZ binding motif have been identified: glutamate receptor interacting protein (GRIP), AMPA receptor-binding protein $(\mathrm{ABP})$, and protein interacting with C-kinase 1 (PICK1). These postsynaptic proteins are involved in the regulation of AMPA receptor trafficking. GRIP and $\mathrm{ABP}$ contain multiple PDZ domains and may form homomultimers and heteromultimers. PICK1 has a single PDZ domain that can interact with GluR2 and GluR3 AMPA receptor subunits and with the catalytic subunit of $\mathrm{PKC}_{\alpha}$. PICK1 can also dimerize at a site distinct from the PDZ domain, thus enabling dimeric PICK1 to link other proteins such as PKC to GluR2 (Perez et al., 2001).

We intracellularly applied synthetic peptides to disrupt the interaction between the ct-PDZ binding motif of GluR2 and different PDZ domains. pep2-SVKI corresponds to the last 11 amino acids of the PDZ binding motif of GluR2, and it includes ser-880, which is believed to be important for PDZ binding. Intracellular application of pep2-SVKI was shown to block the interaction of GluR2/3 with PICK1, GRIP, and ABP. pep2EVKI is an identical peptide, except that serine is exchanged with glutamate to mimic phosphorylation at ser-880. Binding to this mutated peptide was shown to be selective for PICK1, whereas pep2-SVKE serves as an inactive control. Under our conditions, both pep2-SVKI (93.9 $\pm 15.9 \%$ of baseline EPSP amplitudes, $n=$ $6, p>0.05$ ) (Fig. 5A) and the PICK1-selective peptide pep2EVKI $(87.7 \pm 12.6 \%$ of baseline, $n=6, p>0.05)$ (Fig. $5 B$ ) prevented the induction of a significant LTD by the asynchronous pairing protocol. pep2-SVKE had no effect on LTD induction $(58.3 \pm 4.7 \%$ of baseline, $n=6, p<0.05)$ (Fig. $5 C$ ). This strongly supports a role for PICK1 in the mechanism underlying associative LTD.

\section{Postsynaptic mechanism of LTD expression}

Our findings so far would suggest a postsynaptic mechanism for LTD induction. To determine whether an additional presynaptic mechanism is involved in LTD induction, we adopted three independent approaches. First, we analyzed the paired-pulse ratio, i.e., the ratio between the amplitudes of two consecutive EPSPs within a short time interval. A change in this ratio is commonly explained as a modification of presynaptic transmitter release probability (Bender et al., 2006). In a separate set of experiments, LTD was induced by asynchronous pairing, resulting in a synaptic depression to $67.7 \pm 9.0 \%$ of the baseline EPSP amplitude $(n=9, p<0.01)$ (Fig. $6 A)$. Every tenth EPSP was replaced by a double pulse, in which two EPSPs were applied within a time interval of $50 \mathrm{~ms}$; this resulted in a paired-pulse facilitation that
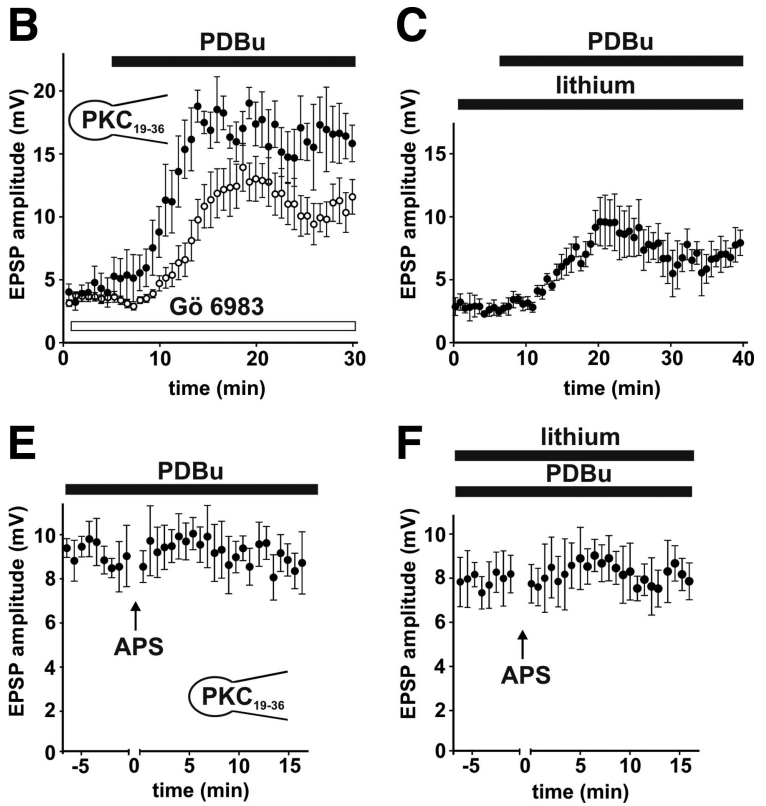

Figure 4. Presynaptic and postsynaptic effects of PKC-activation by a phorbolester. $\boldsymbol{A}$, Wash-in of the phorbolester PDBu (5 $\mu \mathrm{M})$ inhibited the induction of pairing stimulation even in the presence of PDBu.

was stable over the course of the experiment. We compared the paired-pulse ratio before and after induction of LTD and found no significant change (pre LTD, $2.52 \pm 0.24$; post LTD, $2.83 \pm$ $0.31, n=9$ cells, $p>0.05$ ) (Fig. 6A).

Second, we performed a CV analysis of the initial EPSP slopes from the experiments in Figure $1 C$. The averaged $\mathrm{CV}_{\text {post }}^{-2} / \mathrm{CV}_{\text {pre }}^{-2}$ was $0.96 \pm 0.02(n=21)$, which is consistent with a postsynapticinduction mechanism as there is no indication for a change in the presynaptic release probability.

Third, we tested for the involvement of endocannabinoids as retrograde messengers in long-term synaptic depression. The expression of certain forms of spike time-dependent neocortical LTD requires the activity-dependent postsynaptic release of an endocannabinoid, which diffuses retrogradely and binds to presynaptic CB1 cannabinoid receptors. The coincidence of CB1 and presynaptic NMDA receptor activation produces a long-term depression of transmitter release (Bender et al., 2006; Nevian and Sakmann, 2006). Although the onset of synaptic depression was slowed after bath application of the CB1 receptor antagonist AM $251(2 \mu \mathrm{M})$, it did not impair the expression of LTD under our conditions ( $73.1 \pm 9.8 \%$ of baseline, $n=7, p<0.05$ ) (Fig. $6 B$ ). Inclusion of the anandamide membrane transport blocker VDM-11 $(20 \mu \mathrm{M})$ in the recording pipette to block postsynaptic synthesis of the endocannabinoid 2-arachidonylglycerol (Bender et al., 2006) had no effect on LTD $(68.8 \pm 11.9 \%$ of baseline, $n=$ $6, p<0.05$ ) (Fig. 6C). Our findings are therefore consistent with a postsynaptic mechanism of spike time-dependent LTD induction and expression in the hippocampus.

Lithium antagonizes the effects of stress on activated PKC levels and synaptic plasticity

Finally, we examined the involvement of PKC in behaviordependent modulation of synaptic plasticity. Over the last few 

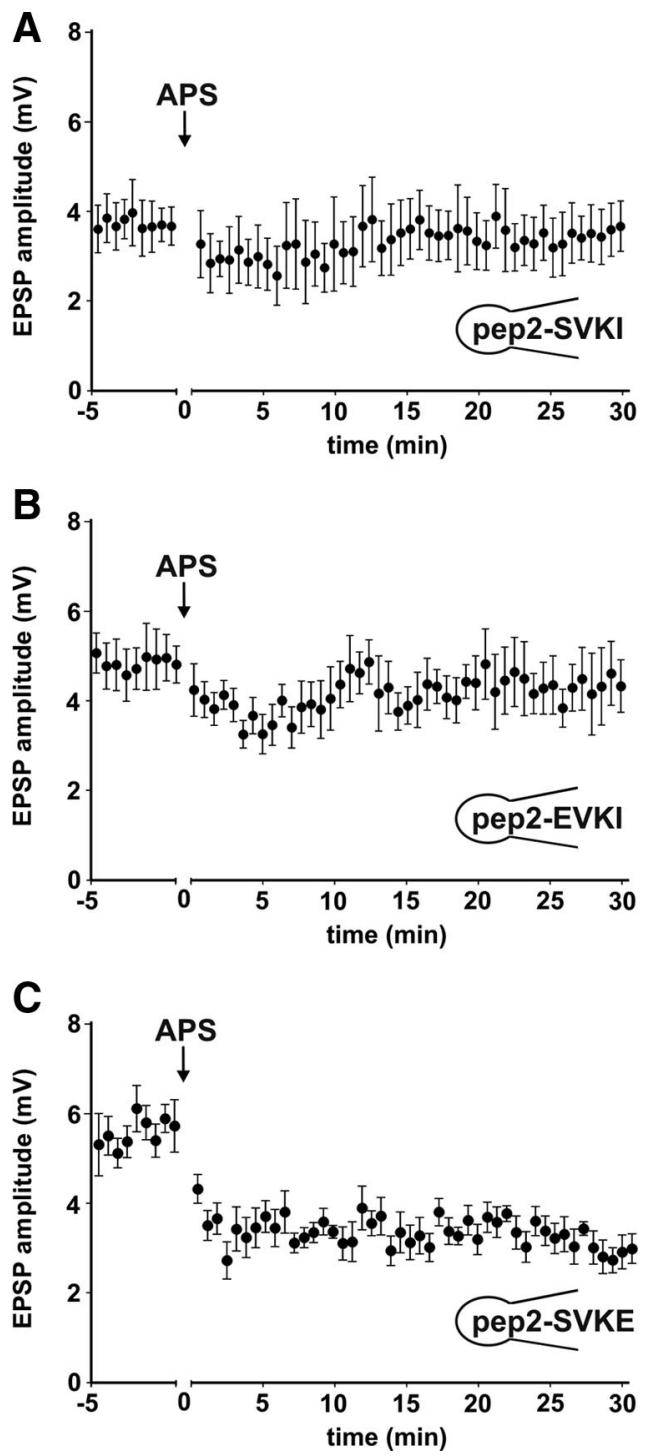

Figure 5. Role of PDZ proteins in the LTD induction mechanism. Synthetic peptides that disrupt the interaction between the PDZ binding motif on the GluR2 subunit of the AMPA receptor and the $\mathrm{PDZ}$ domain on regulating peptides were applied by intracellular injection into the CA1 pyramidal neuron. $\boldsymbol{A}$, Pep2-SVKI blocked the interaction of PICK1, GRIP, and ABP with the PDZ binding motif and inhibited associative LTD. $\boldsymbol{B}$, Pep2-EVKI is selective for PICK1; its intracellular application was sufficient to inhibit LTD. C, Pep2-SVKI is an inactive control and had no effect on LTD induction by asynchronous pairing stimulation (APS).

years, several groups have found a robust modulation of longterm synaptic plasticity by stress. Exposure of rodents to behavioral stress facilitated the induction of LTD and inhibited LTP. This effect was glucocorticoid receptor-dependent (Xu et al., 1998). Moreover, it has been reported that stress upregulates PKC activity (Yang et al., 2004). After demonstrating that lithium inhibits LTD and the effects of the PKC-activating phorbol ester PdBU, we next tested whether lithium, which can be applied in the living animal, would have an effect on the stress-modulation of synaptic plasticity.

To assess the effects of acute stress, we used a combined tail shock/restraint paradigm. Juvenile rats were immobilized in a plastic tube for $30 \mathrm{~min}$, during which 30 electric tail shocks were applied at variable time intervals. This protocol has previously resulted in the production of robust stress responses in different settings (Shors and Thompson, 1992; Yang et al., 2004). All con- trol animals in this set of experiments were injected with saline $1 \mathrm{~h}$ before decapitation.

We first measured the levels of activated PKC in the hippocampus via a Western blot, using an antibody to phospho$\mathrm{PKC} \alpha / \beta$ II. Anti- $\beta$-actin was used to control for equal loading and for quantification. The levels of phosphorylated PKC were not significantly affected by pretreatment of the rats with lithium ( $4 \mathrm{mEquiv} / \mathrm{kg}$ body weight i.p. $1 \mathrm{~h}$ before decapitation); however, pPKC activity was significantly increased after the stress protocol. When lithium was applied systemically $1 \mathrm{~h}$ before initiation of the stress protocol, pPKC activity was not significantly different from control values (luminescence ratios $\mathrm{pPKC} / \beta$-actin: control, $0.95 \pm 0.06$; lithium, $0.84 \pm 0.09$; stress, $1.37 \pm 0.04$; lithium + stress, $0.78 \pm 0.04 ; n=10$ each; Kruskal-Wallis test: $p<0.0001$; Dunn's multiple comparison test: stress vs all other groups, $<0.05$; all other comparisons, not significant) (Fig. 7A).

Exposure to stress resulted in a facilitation of LTD. Synaptic transmission was reduced to $39.5 \pm 6.3 \%$ of baseline, which was significantly different from the findings obtained from nonstressed control rats $(n=8, p<0.01, p<0.05$ vs control LTD) (Fig. $7 B$ ). When lithium was applied by intraperitoneal injection $1 \mathrm{~h}$ before initiation of the stress protocol, the facilitation of LTD was prevented, and asynchronous pairing resulted in a nonsignificant depression $(87.6 \pm 9.3 \%$ of baseline, $n=9, p>$ 0.05) (Fig. 7C).

Acute stress also impaired the induction of LTP. The thetaburst stimulation did not cause a significant change in EPSP amplitudes $(98.7 \pm 20.5 \%$ of baseline EPSP amplitude between 30 and $40 \mathrm{~min}, n=6, p>0.5, p<0.05$ vs control LTP) (Fig. $7 D$ ). In vivo application of lithium abolished the stress-induced inhibition of LTP, and the theta-burst stimulation resulted in a potentiation that was not significantly different from the degree of potentiation observed in nonstressed animals ( $167.5 \pm 36.7 \%$ of baseline, $n=9, p<0.05, p>0.5$ vs control LTP) (Fig. $7 E$ ). These results demonstrate that acute stress upregulates the activity of phosphorylated PKC, facilitates LTD, and impairs LTP induction. Lithium prevents the increase of pPKC levels and the modification of synaptic plasticity by stress.

\section{Discussion}

Given the importance of mGluR activation for associative forms of hippocampal LTD, our study focused on the PLC signal transduction pathway that is activated downstream of mGluR. We found several lines of evidence that indicated that activation of the PLC pathway is necessary for associative LTD. We propose that associative hippocampal LTD is postsynaptically induced and expressed by a PICK1-mediated internalization of AMPA receptors.

Associative LTD is group I mGluR dependent (Normann et al., 2000); however, a subtype specificity has not yet been tested. mGluR5 is expressed in high levels in CA1 pyramidal cells (Fotuhi et al., 1994; Romano et al., 1995; Lujan et al., 1996; Kerner et al., 1997). The findings for mGluR1 have been more discrepant; however, in situ hybridization studies have revealed the expression of mGluR1b and 1d mRNA in principal cells of the hippocampus, including CA1 pyramidal neurons (Shigemoto et al., 1992; Berthele et al., 1998). Moreover, mGluR1b has been detected in human and rodent hippocampal CA1 neurons by immunohistochemistry (Blümcke et al., 1996; Ferraguti et al., 1998). Despite their common coupling mechanism via Gq G-proteins, differential effects of mGluR1 and mGluR5 activation have been described for CA1 pyramidal cells and synaptic transmission at the Schaffer collateral pathway (Mannaioni et al., 2001). The group I 
mGluR agonist (S)-3,5-dihydroxyphenylglycine (DHPG) chemically induces a form of LTD in the hippocampus. Whereas most authors suggest a critical role of mGluR $5 \mathrm{ac}$ tivation for DHPG-LTD (Huber et al., 2001; Faas et al., 2002; Huang and Hsu, 2006), Volk et al. (2006) found that both mGluR1 and mGluR5 inhibition are necessary to block the induction of DHPG-LTD. Similar results were reported for long-term depression of NMDA receptor-mediated transmission at the Schaffer collateral-CA1 synapses (Ireland and Abraham, 2009). Our own findings also suggest that mGluR1 and mGluR5 can fully compensate for each other and both can activate the signaling cascades, i.e., the PLC-PKC pathway, required for LTD induction.

We found that PKC is not universally required for the induction of plasticity in the hippocampus, which indicates a specific role for PKC in NMDA-independent forms of LTD. As an increase of intracellular $\mathrm{Ca}^{2+}$ is necessary for PKC activation, sources of $\mathrm{Ca}^{2+}$ different from the NMDA receptor are needed. As LTD could be inhibited by blocking $\mathrm{IP}_{3}$ receptors with intracellularly applied heparin, the data indicate that $\mathrm{IP}_{3}$-dependent $\mathrm{Ca}^{2+}$ stores are involved in LTD induction in a similar manner as that described by others (Bender et al., 2006). However, in previous work using an identical induction paradigm for LTD, we found that this form of LTD requires the opening of highvoltage activated L- and N-type $\mathrm{Ca}^{2+}$ channels (Normann et al., 2000). The different $\mathrm{Ca}^{2+}$ sources might generate cytosolic and submembrane $\mathrm{Ca}^{2+}$ signals with distinct spatiotemporal profiles. Thus, $\mathrm{a} \mathrm{Ca}^{2+}$-dependent $\mathrm{PKC}$ is a prime candidate for the coincidence detector in spike-timedependent long-term depression (Karmarkar and Buonomano, 2002). For its activation, a temporal coincidence of postsynaptic spiking (opening of voltage-dependent $\mathrm{Ca}^{2+}$ channels by the backpropagating action potential) followed within a short time interval by presynaptic activity (glutamate release activating mGluRs and the PLC pathway) is required.

We further examined how the activation of PKC translates into a sustained downregulation of synaptic transmission and found a prominent role for the PDZ domain-containing protein PICK1. PICK1 is necessary for several forms of synaptic depression (Isaac et al., 2007; Jo et al., 2008). The role of PICK1 in hippocampal LTD is controversial. Two studies that used intracellular infusion of peptides to block PICK1 PDZ domain interactions (similar to the technique used in this study) in NMDA-dependent forms of hippocampal LTD yielded conflicting results. Daw et al. (2000) could not confirm a role for PICK1 in hippocampal LTD, whereas Kim et al. (2001) found a partial block of LTD. Recently, it has been demonstrated that both LTP and LTD are absent in hippocampal CA1 neurons that lack PICK1 and also during blockade of PICK1-PDZ interactions (Terashima et al., 2008).

Masukawa and coworkers (2006) have shown that activation of PKC $\alpha$ causes the translocation of PICK1 to the plasma mem-
B

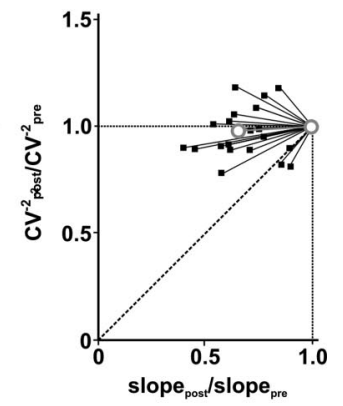

D

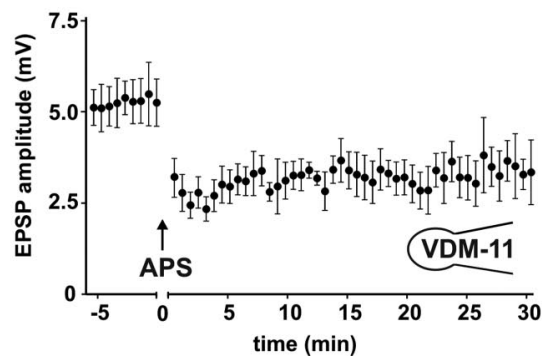

Figure 6. Postsynaptic mechanism of LTD expression. $\boldsymbol{A}$, In a separate set of experiments, every tenth EPSP was replaced by a experiment; this supported a postsynapticmechanism of $L T D$ expression $B C V^{-2}$ was plotted against the mean of the initialEPSP 21 single experiments from Figure 1C, the gray open circles depict the ave normalized $\mathrm{V}^{-2}$. The $\mathrm{CV}$ anasis is

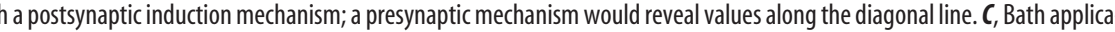
endocannabinoid 2-arachidonylglycerol, did not impair LTD. This makes the involvement of endocannabinoids as retrograde messengers in LTD expression unlikely.

brane. The subtype-specific interaction of PKC $\alpha$ with PICK1 was caused by the binding of the PDZ domain of PICK1 to the PDZbinding site at the $\mathrm{COOH}$ terminus of $\mathrm{PKC} \alpha$. The translocation of PICK1 to the membrane required the activation of PKC $\alpha$, which might phosphorylate PICK1 at the T-82, as well as postsynaptic glutamate receptors.

The exact mechanism by which PICK1 promotes the internalization of AMPA receptors remains to be fully elucidated. It has been proposed that PKC $\alpha$ phosphorylates ser- 880 of GluR2, which is located within the ct-PDZ binding motif (Perez et al., 2001). Furthermore, PICK1 might preferentially bind to the phosphorylated PDZ-binding motif, whereas the interaction with GRIP and ABP might be disrupted (Kim et al., 2001; Perez et al., 2001). PICK1 binding subsequently destabilizes the membrane anchoring of GluR2-containing AMPA receptors and promotes the removal and endocytosis of postsynaptic GluRs (Seidenman et al., 2003).

The interaction between PICK1 and GluR2 is regulated by a calcium-binding domain at the $\mathrm{N}$ terminus of PICK1. A rise of free intracellular $\mathrm{Ca}^{2+}$ from baseline levels to $15 \mu \mathrm{M}$ greatly increases the affinity of PICK1 for GluR2, whereas further increases in $\mathrm{Ca}^{2+}$ decrease the affinity of this interaction (Hanley and Henley, 2005).

Given these findings, we propose a model for associative LTD in the hippocampus in which activation of metabotropic glutamate receptors and $\mathrm{Ca}^{2+}$ influx through voltage-activated $\mathrm{Ca}^{2+}$ channels are the initial triggers that ultimately result in AMPA 
A
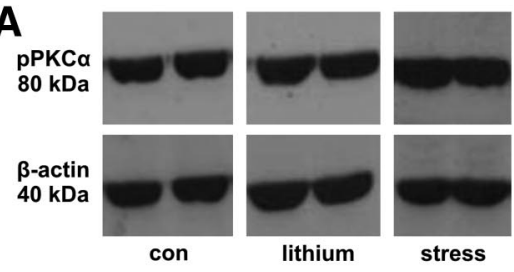

B

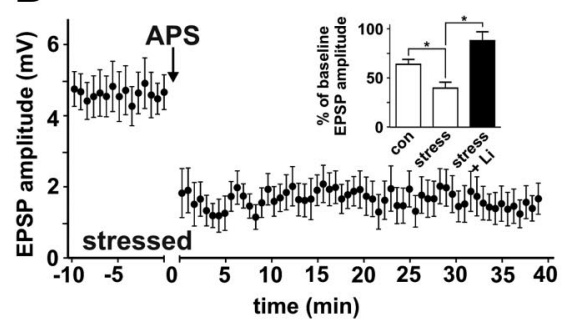

D

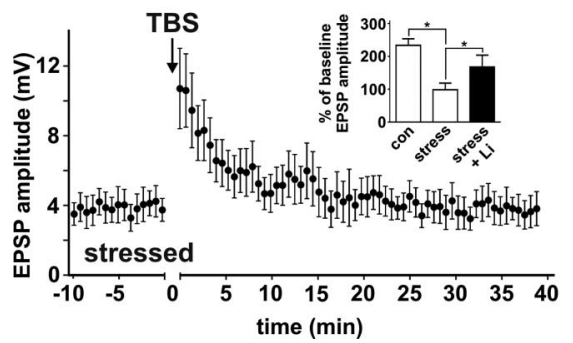

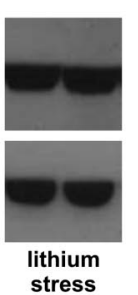

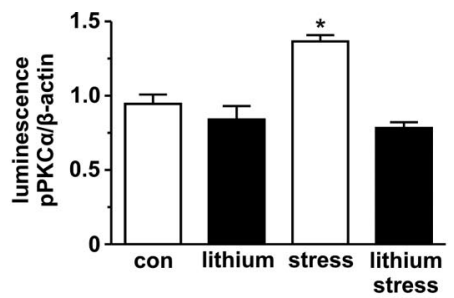

C

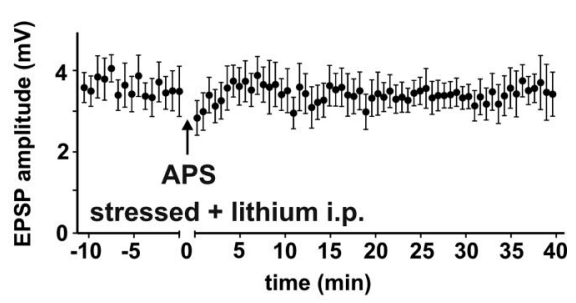

E

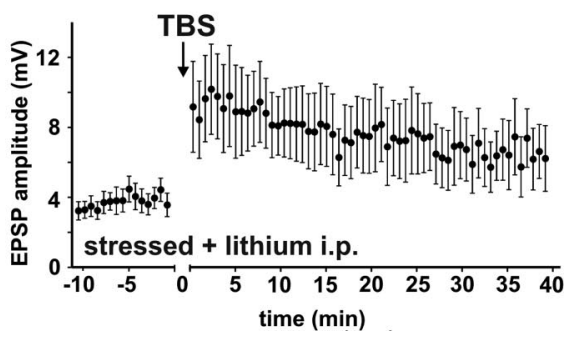

Figure 7. Lithium antagonizes the effects of stress on PPKC activity and synaptic plasticity. $A$, The levels of phosphorylated PKC $\alpha / \beta \|$ and $\beta$-actin in the hippocampus were determined by Western blot. Representativescans show results from both hippocampi of one animal in each group. Luminescence ratios (pPKC $\alpha / \beta$-actin) were calculated for each hippocampus and averaged within a group containing five animals each. Significance was assessed using a Kruskal-Wallis test. Behavioral stress, induced by a combined tail shock/restrained paradigm for $1 \mathrm{~h}$, upregulated pPKC activity; this upregulation was prevented by pretreatment with lithium. $\boldsymbol{B}$, Stress was used as a nonpharmacological tool with which to modulate synaptic plasticity. The stress protocol significantly increased the amount of LTD induction by asynchronous pairing stimulation (APS). C, Intraperitoneal injection of lithium in advance of the stress protocol prevented the induction of LTD. D, Acute stress caused a reduction in the magnitude of LTP induced by theta-burst stimulation (TBS). $\boldsymbol{E}$, After intraperitoneal application of lithium before the stress protocol, LTP was restored. Li, Lithium; con, control.

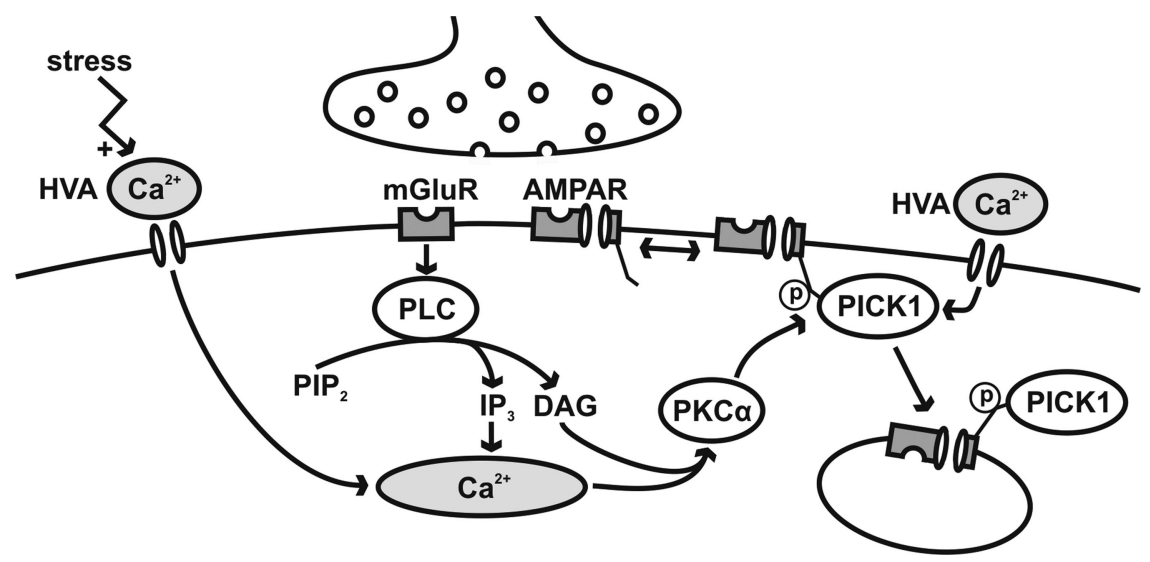

Figure 8. A model for associative LTD in the hippocampus. PKC and PICK1 are the coincidence detectors for the activation of metabotropic glutamate receptors and the $\mathrm{Ca}^{2+}$ influx through voltage-dependent $\mathrm{Ca}^{2+}$ channels. PICK1 mediates the internalization of AMPA receptors (AMPAR), which reduces the synaptic transmission of the glutamatergic synapse. Stress increases $\mathrm{Ca}^{2+}$ currents and thereby facilitates LTD.

receptor internalization and depression of synaptic transmission (Fig. 8). mGluR receptor activation is positively coupled to phospholipase $\mathrm{C}$, which in turn causes the release of $\mathrm{Ca}^{2+}$ from intracellular stores by $\mathrm{IP}_{3}$ and the activation of PKC via DAG.
Activated PKC is responsible for the transfer of PICK1 to the cell membrane and the phosphorylation of ser-880 within the ct-PDZ binding motif of GluR2. PICK1 binds to GluR2 and mediates the internalization of functional AMPA receptors and the stabilization of the extrasynaptic AMPA receptor pool.

This process is regulated by free $\mathrm{Ca}^{2+}$ at the level of PKC and PICK1, both of which are $\mathrm{Ca}^{2+}$ dependent. The sources of the relatively low $\mathrm{Ca}^{2+}$ increase in LTD are high-voltage-activated $\mathrm{Ca}^{2+}$ channels and intracellular $\mathrm{IP}_{3}$-dependent $\mathrm{Ca}^{2+}$ stores. Action potentials open voltage-activated $\mathrm{Ca}^{2+}$ channels. Hence, in a situation where an AP precedes the EPSP, $\mathrm{Ca}^{2+}$ will be present at the time that the mGluRdependent pathway is activated. The interval sensitivity of this response is derived from the $\mathrm{Ca}^{2+}$ decay rate. In nonassociative forms of LTD (such as NMDA-dependent low-frequency stimulation of the Schaffer collaterals), sustained low-level activation of NMDA receptors might be an alternative $\mathrm{Ca}^{2+}$ influx pathway. In this model, PKC and PICK1 act cooperatively as coincidence detectors for the coordinated presynaptic and postsynaptic activity that is necessary for LTD induction.

Our model is consistent with a purely postsynaptic model of the induction and expression of associative LTD in the hippocampus. Analysis of the paired pulse ratio after LTD and a CV analysis of the EPSP slopes immediately before and after the LTD induction protocol supported this notion. This might be different in the neocortex where the involvement of retrograde-endocannabinoid signaling in the mechanism of a mGluR-dependent form of LTD has been described (Bender et al., 2006).

As the induction of LTD and LTP depend on different signal-transduction pathways, we tested whether different forms of plasticity might be differentially modulated by the behavioral context of the animal. We found that acute stress facilitated LTD and inhibited LTP; this confirmed earlier results in which this effect was glucocorticoid receptor-dependent and could be modulated by serotonergic and antidepressive agents (Shors et al., 1989; Xu et al., 1998; Yang et al., 2004). In a previous study, we showed that the induction of LTD was facilitated after chronic mild stress (an animal model of depression). In contrast, theta-burstinduced LTP was unaffected by the chronic mild stress paradigm (Holderbach et al., 2007). This shows that although both LTD and LTP can be affected by stress, not only does LTD appear to be more sensitive, but the underlying mechanisms might be different. 
Results from several brain regions suggest an upregulation of PKC activity by behavioral stress. In the hippocampus, Yang and coworkers (2004) reported an increase in PKC activity in stressed rats and also demonstrated that the stress-induced facilitation of LTD and suppression of LTP could be prevented by intrahippocampal administration of a specific PKC inhibitor. In the prefrontal cortex, stress increased PKC activity and impaired cognitive function (Birnbaum et al., 2004). A probable mechanism for the increased activity of PKC after stress is that the increase in $\mathrm{Ca}^{2+}$ influx through high-voltage activated $\mathrm{Ca}^{2+}$ channels results in the activation of $\mathrm{Ca}^{2+}$-sensitive isoforms of PKC. Corticosteroids have been repeatedly shown to increase voltage-dependent $\mathrm{Ca}^{2+}$ conductances by a mechanism that requires DNA binding of glucocorticoid receptor homodimers and modulation of $\mathrm{Ca}^{2+}$ channel subunit expression (Chameau et al., 2007). Alternatively, the stress-induced upregulation of PKC activity might originate from the activation of the BDNF/ERK1/2cascade (Yang et al., 2004).

Using Western blot, we found increased levels of phosphorylated PKC after exposure to stress, which could be normalized by lithium pretreatment. In the absence of specific PKC activation, lithium had no significant effect on pPKC levels. Consistent with these findings, stress facilitated LTD induction, whereas lithium pretreatment completely blocked LTD induction after stress. This most probably occurred by inhibition of both the stressinduced and the mGluR-induced activation of PKC. It is interesting to note that lithium had no effect on the induction of LTP under control conditions but prevented the downregulation of LTP after stress. This suggests that under stress conditions, LTDlike mechanisms, i.e., the activation of PKC and the internalization of AMPA receptors, might counteract the mechanisms of LTP expression.

The role of GSK-3 in the inhibition of LTD by lithium is ambiguous. During inhibition of GSK-3, the amount of LTD was reduced compared with control conditions; however, this difference did not reach statistical significance. A decisive influence of GSK-3 on associative LTD under our conditions is improbable for several reasons. Very high concentrations of lithium (20 mM) have been necessary to block NMDA-dependent LTD (Peineau et al., 2007), and we did not observe any increased LTP in the presence of lithium, which should have been expected if the low concentrations of lithium used in our experiments would significantly inhibit GSK-3. Moreover, phosphorylation of GSK-3 by PKC $\alpha$ has been shown to result in its specific inactivation, which might support a primary role for the PKC pathway (Goode et al., 1992; Fang et al., 2000).

Lithium is one of the few medications in clinical use that modulates PKC activity. It is used broadly in psychiatry for both acute and chronic treatment of affective disorders. At the molecular level, lithium alters both structural and functional plastic changes induced by stress in the hippocampus. Chronic lithium has been shown to prevent morphological remodeling of apical dendrites of CA3 pyramidal cells induced by stress and to enhance hippocampal neurogenesis (Chen et al., 2000; Wood et al., 2004). On the other hand, lithium might reverse the neurobiological effects of stress on functional synaptic plasticity, as shown in our experiments. Disturbed structural and functional brain plasticity has been implicated in the pathophysiology of affective disorders (Castrén, 2005; Normann et al., 2007). Lithium might protect limbic circuitry from the effects of excessive stress; we hypothesize that this might contribute to the mood-stabilizing effects of lithium.

\section{References}

Bender VA, Bender KJ, Brasier DJ, Feldman DE (2006) Two coincidence detectors for spike timing-dependent plasticity in somatosensory cortex. J Neurosci 26:4166-4177.

Berthele A, Laurie DJ, Platzer S, Zieglgänsberger W, Tölle TR, Sommer B (1998) Differential expression of rat and human type I metabotropic glutamate receptor splice variant messenger RNAs. Neuroscience 85:733-749.

Birnbaum SG, Yuan PX, Wang M, Vijayraghavan S, Bloom AK, Davis DJ, Gobeske KT, Sweatt JD, Manji HK, Arnsten AF (2004) Protein kinase C overactivity impairs prefrontal cortical regulation of working memory. Science 306:882-884.

Bitran JA, Manji HK, Potter WZ, Gusovsky F (1995) Down-regulation of PKC alpha by lithium in vitro. Psychopharmacol Bull 31:449-452.

Blümcke I, Behle K, Malitschek B, Kuhn R, Knöpfel T, Wolf HK, Wiestler OD (1996) Immunohistochemical distribution of metabotropic glutamate receptor subtypes mGluR1b, mGluR2/3, mGluR4a and mGluR5 in human hippocampus. Brain Res 736:217-226.

Bolshakov VY, Siegelbaum SA (1994) Postsynaptic induction and presynaptic expression of hippocampal long-term depression. Science 264:1148-1152.

Bortolotto ZA, Collingridge GL (2000) A role for protein kinase C in a form of metaplasticity that regulates the induction of long-term potentiation at CA1 synapses of the adult rat hippocampus. Eur J Neurosci 12:4055-4062.

Bredt DS, Nicoll RA (2003) AMPA receptor trafficking at excitatory synapses. Neuron 40:361-379.

Castrén E (2005) Is mood chemistry? Nat Rev Neurosci 6:241-246.

Chameau P, Qin Y, Spijker S, Smit G, Joëls M (2007) Glucocorticoids specifically enhance L-type calcium current amplitude and affect calcium channel subunit expression in the mouse hippocampus. J Neurophysiol 97:5-14.

Chen G, Rajkowska G, Du F, Seraji-Bozorgzad N, Manji HK (2000) Enhancement of hippocampal neurogenesis by lithium. J Neurochem 75:1729-1734.

Dan Y, Poo MM (2006) Spike timing-dependent plasticity: from synapse to perception. Physiol Rev 86:1033-1048.

Daw MI, Chittajallu R, Bortolotto ZA, Dev KK, Duprat F, Henley JM, Collingridge GL, Isaac JT (2000) PDZ proteins interacting with C-terminal GluR2/3 are involved in a PKC-dependent regulation of AMPA receptors at hippocampal synapses. Neuron 28:873-886.

Faas GC, Adwanikar H, Gereau RW 4th, Saggau P (2002) Modulation of presynaptic calcium transients by metabotropic glutamate receptor activation: a differential role in acute depression of synaptic transmission and long-term depression. J Neurosci 22:6885-6890.

Fang X, Yu SX, Lu Y, Bast RC Jr, Woodgett JR, Mills GB (2000) Phosphorylation and inactivation of glycogen synthase kinase 3 by protein kinase $A$. Proc Natl Acad Sci U S A 97:11960-11965.

Ferraguti F, Conquet F, Corti C, Grandes P, Kuhn R, Knopfel T (1998) Immunohistochemical localization of the mGluRlbeta metabotropic glutamate receptor in the adult rodent forebrain: evidence for a differential distribution of mGluR1 splice variants. J Comp Neurol 400:391-407.

Fotuhi M, Standaert DG, Testa CM, Penney JB Jr, Young AB (1994) Differential expression of metabotropic glutamate receptors in the hippocampus and entorhinal cortex of the rat. Brain Res Mol Brain Res 21:283-292.

Goode N, Hughes K, Woodgett JR, Parker PJ (1992) Differential regulation of glycogen synthase kinase- 3 beta by protein kinase $\mathrm{C}$ isotypes. J Biol Chem 267:16878-16882.

Hanley JG, Henley JM (2005) PICK1 is a calcium-sensor for NMDAinduced AMPA receptor trafficking. EMBO J 24:3266-3278.

Hernández F, Borrell J, Guaza C, Avila J, Lucas JJ (2002) Spatial learning deficit in transgenic mice that conditionally over-express GSK-3beta in the brain but do not form tau filaments. J Neurochem 83:1529-1533.

Higashitani Y, Kudo Y, Ogura A, Kato H (1990) Acute effects of lithium on synaptic transmission in rat hippocampus studied in vitro. Biol Psychiatry 27:174-182.

Holderbach R, Clark K, Moreau JL, Bischofberger J, Normann C (2007) Enhanced long-term synaptic depression in an animal model of depression. Biol Psychiatry 62:92-100.

Hooper C, Markevich V, Plattner F, Killick R, Schofield E, Engel T, Hernandez F, Anderton B, Rosenblum K, Bliss T, Cooke SF, Avila J, Lucas JJ, Giese KP, 
Stephenson J, Lovestone S (2007) Glycogen synthase kinase-3 inhibition is integral to long-term potentiation. Eur J Neurosci 25:81-86.

Hori T, Takai Y, Takahashi T (1999) Presynaptic mechanism for phorbol ester-induced synaptic potentiation. J Neurosci 19:7262-7267.

House C, Kemp BE (1987) Protein kinase C contains a pseudosubstrate prototope in its regulatory domain. Science 238:1726-1728.

Huang CC, Hsu KS (2006) Sustained activation of metabotropic glutamate receptor 5 and protein tyrosine phosphatases mediate the expression of (S)-3,5-dihydroxyphenylglycine-induced long-term depression in the hippocampal CA1 region. J Neurochem 96:179-194.

Huber KM, Kayser MS, Bear MF (2000) Role for rapid dendritic protein synthesis in hippocampal mGluR-dependent long-term depression. Science 288:1254-1257.

Huber KM, Roder JC, Bear MF (2001) Chemical induction of mGluR5- and protein synthesis-dependent long-term depression in hippocampal area CA1. J Neurophysiol 86:321-325.

Ireland DR, Abraham WC (2009) Mechanisms of group I mGluRdependent long-term depression of NMDA receptor-mediated transmission at Schaffer collateral-CA1 synapses. J Neurophysiol 101:1375-1385.

Isaac JT, Ashby M, McBain CJ (2007) The role of the GluR2 subunit in AMPA receptor function and synaptic plasticity. Neuron 54:859-871.

Jo J, Heon S, Kim MJ, Son GH, Park Y, Henley JM, Weiss JL, Sheng M, Collingridge GL, Cho K (2008) Metabotropic glutamate receptormediated LTD involves two interacting $\mathrm{Ca}(2+)$ sensors, NCS-1 and PICK1. Neuron 60:1095-1111.

Karmarkar UR, Buonomano DV (2002) A model of spike-timing dependent plasticity: one or two coincidence detectors? J Neurophysiol 88:507-513.

Kerner JA, Standaert DG, Penney JB Jr, Young AB, Landwehrmeyer GB (1997) Expression of group one metabotropic glutamate receptor subunit mRNAs in neurochemically identified neurons in the rat neostriatum, neocortex, and hippocampus. Brain Res Mol Brain Res 48:259-269.

Kim CH, Chung HJ, Lee HK, Huganir RL (2001) Interaction of the AMPA receptor subunit GluR2/3 with PDZ domains regulates hippocampal long-term depression. Proc Natl Acad Sci U S A 98:11725-11730.

Klein PS, Melton DA (1996) A molecular mechanism for the effect of lithium on development. Proc Natl Acad Sci U S A 93:8455-8459.

Lisman J (1989) A mechanism for the Hebb and the anti-Hebb processes underlying learning and memory. Proc Natl Acad Sci U S A 86:95749578.

Lujan R, Nusser Z, Roberts JD, Shigemoto R, Somogyi P (1996) Perisynaptic location of metabotropic glutamate receptors mGluR1 and mGluR5 on dendrites and dendritic spines in the rat hippocampus. Eur J Neurosci 8:1488-1500.

Manji HK, Etcheberrigaray R, Chen G, Olds JL (1993) Lithium decreases membrane-associated protein kinase $\mathrm{C}$ in hippocampus: selectivity for the alpha isozyme. J Neurochem 61:2303-2310.

Manji HK, Bersudsky Y, Chen G, Belmaker RH, Potter WZ (1996) Modulation of protein kinase $\mathrm{C}$ isozymes and substrates by lithium: the role of myo-inositol. Neuropsychopharmacology 15:370-381.

Mannaioni G, Marino MJ, Valenti O, Traynelis SF, Conn PJ (2001) Metabotropic glutamate receptors 1 and 5 differentially regulate CA1 pyramidal cell function. J Neurosci 21:5925-5934.

Masukawa K, Sakai N, Ohmori S, Shirai Y, Saito N (2006) Spatiotemporal analysis of the molecular interaction between PICK1 and PKC. Acta Histochem Cytochem 39:173-181.

Nevian T, Sakmann B (2006) Spine $\mathrm{Ca}^{2+}$ signaling in spike-timingdependent plasticity. J Neurosci 26:11001-11013.

Normann C, Peckys D, Schulze CH, Walden J, Jonas P, Bischofberger J (2000) Associative long-term depression in the hippocampus is dependent on postsynaptic N-type $\mathrm{Ca}^{2+}$ channels. J Neurosci 20:8290-8297.

Normann C, Schmitz D, Fürmaier A, Döing C, Bach M (2007) Long-term plasticity of visually evoked potentials in humans is altered in major depression. Biol Psychiatry 62:373-380.

Oliet SH, Malenka RC, Nicoll RA (1997) Two distinct forms of long-term depression coexist in CA1 hippocampal pyramidal cells. Neuron 18:969-982.

Peineau S, Taghibiglou C, Bradley C, Wong TP, Liu L, Lu J, Lo E, Wu D, Saule E, Bouschet T, Matthews P, Isaac JT, Bortolotto ZA, Wang YT, Collingridge GL (2007) LTP inhibits LTD in the hippocampus via regulation of GSK3beta. Neuron 53:703-717.
Peineau S, Bradley C, Taghibiglou C, Doherty A, Bortolotto ZA, Wang YT, Collingridge GL (2008) The role of GSK-3 in synaptic plasticity. Br J Pharmacol 153 [Suppl 1]:S428-S437.

Perez JL, Khatri L, Chang C, Srivastava S, Osten P, Ziff EB (2001) PICK1 targets activated protein kinase Calpha to AMPA receptor clusters in spines of hippocampal neurons and reduces surface levels of the AMPAtype glutamate receptor subunit 2. J Neurosci 21:5417-5428.

Rhee JS, Betz A, Pyott S, Reim K, Varoqueaux F, Augustin I, Hesse D, Südhof TC, Takahashi M, Rosenmund C, Brose N (2002) Beta phorbol esterand diacylglycerol-induced augmentation of transmitter release is mediated by Munc13s and not by PKCs. Cell 108:121-133.

Romano C, Sesma MA, McDonald CT, O’Malley K, Van den Pol AN, Olney JW (1995) Distribution of metabotropic glutamate receptor mGluR5 immunoreactivity in rat brain. J Comp Neurol 355:455-469.

Schmidt-Hieber C, Jonas P, Bischofberger J (2004) Enhanced synaptic plasticity in newly generated granule cells of the adult hippocampus. Nature 429:184-187.

Seidenman KJ, Steinberg JP, Huganir R, Malinow R (2003) Glutamate receptor subunit 2 Serine 880 phosphorylation modulates synaptic transmission and mediates plasticity in CA1 pyramidal cells. J Neurosci 23:9220-9228.

Selig DK, Lee HK, Bear MF, Malenka RC (1995) Reexamination of the effects of MCPG on hippocampal LTP, LTD, and depotentiation. J Neurophysiol 74:1075-1082.

Shigemoto R, Nakanishi S, Mizuno N (1992) Distribution of the mRNA for a metabotropic glutamate receptor (mGluR1) in the central nervous system: an in situ hybridization study in adult and developing rat. J Comp Neurol 322:121-135.

Shors TJ, Thompson RF (1992) Acute stress impairs (or induces) synaptic long-term potentiation (LTP) but does not affect paired-pulse facilitation in the stratum radiatum of rat hippocampus. Synapse 11:262-265.

Shors TJ, Seib TB, Levine S, Thompson RF (1989) Inescapable versus escapable shock modulates long-term potentiation in the rat hippocampus. Science 244:224-226.

Stanton PK (1995) Transient protein kinase C activation primes long-term depression and suppresses long-term potentiation of synaptic transmission in hippocampus. Proc Natl Acad Sci U S A 92:1724-1728.

Terashima A, Pelkey KA, Rah JC, Suh YH, Roche KW, Collingridge GL, McBain CJ, Isaac JT (2008) An essential role for PICK1 in NMDA receptor-dependent bidirectional synaptic plasticity. Neuron 57:872882.

Valenti O, Conn PJ, Marino MJ (2002) Distinct physiological roles of the Gq-coupled metabotropic glutamate receptors co-expressed in the same neuronal populations. J Cell Physiol 191:125-137.

Volk LJ, Daly CA, Huber KM (2006) Differential roles for group 1 mGluR subtypes in induction and expression of chemically induced hippocampal long-term depression. J Neurophysiol 95:2427-2438.

Wang HY, Friedman E (1989) Lithium inhibition of protein kinase C activation-induced serotonin release. Psychopharmacology (Berl) 99:213-218.

Wang HY, Johnson GP, Friedman E (2001) Lithium treatment inhibits protein kinase $\mathrm{C}$ translocation in rat brain cortex. Psychopharmacology (Berl) 158:80-86.

Wang JH, Feng DP (1992) Postsynaptic protein kinase C essential to induction and maintenance of long-term potentiation in the hippocampal CA1 region. Proc Natl Acad Sci U S A 89:2576-2580.

Wierda KD, Toonen RF, de Wit H, Brussaard AB, Verhage M (2007) Interdependence of PKC-dependent and PKC-independent pathways for presynaptic plasticity. Neuron 54:275-290.

Wood GE, Young LT, Reagan LP, Chen B, McEwen BS (2004) Stressinduced structural remodeling in hippocampus: prevention by lithium treatment. Proc Natl Acad Sci U S A 101:3973-3978.

Xu L, Holscher C, Anwyl R, Rowan MJ (1998) Glucocorticoid receptor and protein/RNA synthesis-dependent mechanisms underlie the control of synaptic plasticity by stress. Proc Natl Acad Sci U S A 95:3204-3208.

Yang CH, Huang CC, Hsu KS (2004) Behavioral stress modifies hippocampal synaptic plasticity through corticosterone-induced sustained extracellular signal-regulated kinase/mitogen-activated protein kinase activation. J Neurosci 24:11029-11034. 